The very fit man had the highest rise, from 0.9 to $10.9 \mu \mathrm{g} / \mathrm{l}$. In contrast, the level in the older Greek runner remained virtually unchanged $(0.8$ and $1.0 \mu \mathrm{g} / 1)$.

Our investigation confirms the significant rise of plasma GH previously reported after physical exercise. ${ }^{1-3}$ This work is one of a series of studies on the effects of physical exercise on plasma hormones and muscular metabolism. We hope to find tests to distinguish in advance between men who are fit enough to run the marathon and those for whom it may be dangerous. ${ }^{4}$ That such tests may be necessary has already been demonstrated by the case of Philippides, the dispatch-runner who died on arrival at Athens after the Battle of Marathon on 22 September 490 BC. ${ }^{5}$

SIRKKA-LIISA KARONEN H ADLERCREUTZ

University Department of Clinical Chemistry,

Meilahti Hosp.tal,

A DESSYPRIS

University Endocrine Research Unit,

Minerva Foundation

1 Sutton, J et al, Medical fournal of Australia, 1972, 2,127

Hartley, L H, et al, fournal of Applied Physiology,

Sutton. J R, et al, British Medical fournal, 1973,

, Shephard, $\mathbf{R} \mathrm{H}$, and Pandit, V, 1974, 229, 1602 .

5 Fowler, H W, and Fowler, F G (trans), The Works of Lucian of Samosata, vol 2, p 36 . London, Oxford University Press, 1949.

\section{Pregnancy in adolescence}

SIR,-Your leading article "Pregnancy in adolescence" (20 September, p 665) has prompted me to write about Hayward House, which is one of a number of family group homes run by the Messenger House Trust.

Hayward House was opened in March 1975 for young West Indian mothers aged 14 to 18 years in order that they may keep their babies. There is an increasing number of these schoolgirls who do not wish to give their babies for adoption, who have been rejected by their families, and who in the normal course of events return to school while their children are placed in residential nurseries or foster homes and are reclaimed by the mothers when they are of schoolleaving age. In our experience in these circumstances no normal bonding between mother and child has developed; in one case a much damaged child of 4 years was in due course given up for adoption and in another the toddler, having returned to the mother, suffered severe burns before being taken away from the mother. In contrast Hayward House is a happy place where five girls care for their children and at times for each other's, and with home tuition it is hoped that these mothers will mature and in due course be able to manage in council flats at the age of 18. Some may make early marriages, and with our system of aftercare perhaps be successful in bringing up their families in a more adult manner than without the care of the voluntary visitors and the work that we have done together at our large group meetings, which are held with the mothers from the other houses and with members from the social services also present.

I feel that many similar small houses should be leased to voluntary bodies by the local authorities where these young mothers could live and that this is an effective way of preventing emotional damage to young children. We shall be opening our next house, to be named after the late Dr Donald Winnicott, in the next few months. Further particulars may be obtained from the address below.

JOSEPHINE M LOMAX-SIMPSON

Messenger House Trust

London SW19 4AS

\section{"Caecal squelch" and appendicitis}

SIR,-At times the differential diagnosis of acute appendicitis is difficult. The history of diarrhoea or headaches and the finding of a high fever $\left(>39.5^{\circ} \mathrm{C}\right)$, inflamed fauces, and diffuse lymphadenopathy are well-known features that point away from the diagnosis of acute appendicitis.

We would like to emphasise an additiona sign which we have found very helpful in deciding whether an appendicectomy is necessary-when a "caecal squelch" is palpable in the right iliac fossa an acutely inflamed appendix is unlikely to be present.

During the past 18 months over 400 patients with the possible diagnosis of acute appendicitis have been seen by one surgical team at this hospital. The presence or absence of fluid bowel contents that "squelch" on pressing in the right iliac fossa has been particularly noted. During this time there were only three patients who had a "caecal squelch" and who subsequently had acutely inflamed appendices removed. These three all had otherwise characteristic histories and signs of appendicitis. Significantly, they all had a distal appendicitis, the proximal parts being macroscopically normal. Whipps Cross Hospital,

B V PALMER London E11

\section{Isolated glomerulonephritis with mesangial} IgA deposition

SIR,-In their paper on this subject (13 September, p 611) Dr J G P Sissons and his colleagues are incorrect in claiming that "no other series has been reported from this country." We reported the occurrence of recurrent haematuria and mesangial IgA deposition in a paper given to the Pathological Society in January 1973. The features of six patients with this clinioopathological association were reported in the Fournal of Clinical Pathology.

At this hospital between 1971 and 1975 the association of recurrent haematuria with mesangial IgA deposition was seen in 16 $(7 \%)$ out of 220 renal patients whose biopsy specimens were examined by immunofluorescent techniques (transplants excluded). "Entities" are notoriously ill-defined in nephrology, but recurrent haematuria with mesangial IgA is seen sufficiently frequently for it to be given a special place. Until the aetiology and pathogenesis have been clarified "Berger's nephropathy" seems a useful eponym for this association of recurrent haematuria with mesangial IgA. ${ }^{2}$

It seems likely that other patients with mesangial IgA deposition and "isolated glomerulonephritis" but who present with symptoms other than haematuria also belong to this group. The pattern of immunoglobulin deposition in the glomeruli is more likely to reflect the underlying disease process than is the clinical presentation.

D R DAVIES
J R TIGHE
N F JoNES
St Thomas's Hospital Medical School,
London SE1
1 Davies, D R, et al, fournal of Clinical Patho!ogy,
1973, 26, 672. al, Actualités néphrologiques de
2 Berger, J, et al, 1967, 172.
l'Hôpital Necker, 19.

\section{Prescriptions for pill}

SIR,-It may be helpful to draw to the attention of doctors who are used to giving prescriptions for six packets of the pill at a time the fact that there are 13 menstrual months in a calendar year. On the basis of being given two six-monthly prescriptions patients will return at the end of the year, a month before they are eligible to complete another Form FP 1001. In our practice we intend to issue a seven-month prescription between 1 January and 30 June each year in order to try and avoid this pitfall.

Old Windsor D S JEFFERY

\section{Fibrinogen uptake scanning}

SIR,-In Dr V C Roberts's plea for standardisation of the interpretation of the fibrinogen uptake test (23 August, p 455) we find several aspects in which his experience differs from our own, although our techniques of leg reading appear to be identical.

In the first place, our patients receive their dose of ${ }^{125}$ I-fibrinogen immediately after operation and we cannot therefore compare postoperative with preoperative readings. Secondly, we find background radiation negligible and readings virtually the same with and without reference to this parameter.

More fundamentally, however, the pattern of leg counts in our patients without isotopic evidence of venous thrombosis is significantly different from his. Our own figures are taken from the records of 50 randomly selected patients. We have averaged the six-day percentage counts at each of 10 points on the leg and deduced the standard errors of means from the means of the standard deviations.

The mean counts in our patients at positions $1,2,3,4,5$, and 9 differ significantly from his (the $t$ values being $4 \cdot 81$, $6 \cdot 11,4 \cdot 27,2 \cdot 00,2 \cdot 00$, and $2 \cdot 56$ respectively). The six-day means (SEM in parentheses) in Dr Roberts's series are: $31(1 \cdot 2), 28$ (1.0), $27(1 \cdot 0), 27(0.9), 27(0.9), 28(1 \cdot 0), 29(1.0)$, $29(1.0), 28(1.0)$, and $26(1.0)$ compared with our figures of $41(1 \cdot 7), 39$ $(1 \cdot 5), 34,(1 \cdot 3), 30(1 \cdot 2), 30(1 \cdot 2), 30(1 \cdot 2)$, $27(1 \cdot 2), 26(1 \cdot 2), 24(1 \cdot 2)$, and $23(1 \cdot 3)$. In our experience it is usual for the percentage counts to fall progressively from groin to ankle.

Scarborough Hospital

A V Pollock

MARY EVANS

\section{Methods of laparoscopic sterilisation}

SIR,-We read with interest Dr G Hughes and Mr W A Liston's retrospective comparison of laparoscopic tubal diathermy and abdominal tubal ligation (13 September, p 